\title{
Market, Network, Hierarchy: Emerging Mechanisms of Governance in Business Process Management
}

\author{
Bjoern Niehaves and Ralf Plattfaut \\ Westfälische Wilhelms-Universität Münster, European Research Center for Information \\ Systems, Leonardo-Campus 3, 48149 Münster, Germany \\ \{bjoern.niehaves, ralf.plattfaut\} @ercis.uni-muenster.de
}

\begin{abstract}
Both financial pressure and customer and service-quality orientation force governments to "innovate their processes." With governmental processes affecting a large variety of stakeholders both inside and outside the government sector, involving these stakeholders in process innovation becomes an important means of increasing know-how, capacity, and ultimately ensure the legitimacy and acceptance of reform efforts. We contribute to the study of collaborative process innovation by applying a governance theory perspective, in order to understand the factors that impact on collaboration. Our quantitative study of 357 local governments reveals that, with an increasing maturity in process innovation, all types of collaboration (market, network, hierarchy) are increasing in importance. Moreover, we find that, under financial stress, governments tend to involve network partners (e.g. other local governments) in process innovation, while a lack of process management knowledge leads to market-oriented collaboration with consultants. We derive implications for management practice and discuss how the study enhances our understanding of process innovation and collaboration in the public sector.
\end{abstract}

Keywords: Public Sector, Business Process Management, Collaboration, Innovation Networks, Quantitative Study.

\section{Introduction}

Innovation networks and collaboration have become key themes in eGovernment research. With governments being under immense reform pressure, various approaches attempt to modernize, improve or restructure public administrations, be it practices in the context of New Public Management [1] or eGovernment [2]. Due to this high pressure, the diversity of demands, and new areas of responsibility, local governments rely increasingly on innovation networks. Various internal and external actors are involved in reform processes, such as software and consulting companies, local government associations [3], or individual citizens. Influential research in innovation management (for instance [4] and [5]) suggests that access to external knowledge, in order to enlarge an organization's own pool of capabilities, is a key to innovation success. External actors can contribute by providing distinct perspectives on the topic at issue, as well as domain-specific knowledge which does not exist in the public sector organization itself. With the importance of collaboration in eGovernment being widely acknowledged, [6-8], current eGovernment literature fails to 
provide a general framework that integrates distinct types of collaboration and, second, to understand to empirically investigate contextual factors that impact on collaboration schemata.

Process innovation is an essential element of eGovernment and public sector reform [9-14]. It seems to have established as common sense that municipalities need to innovate their business processes: cost-cutting, especially in times of the financial crisis, as well as citizen and service quality orientation, have led to calls for a program of process innovation in public organizations [12]. Most recently, for all European member states, the EU Service Directive requires the establishment of a single point of contact for all administrative services, providing yet another major impulse for public sector process innovation [15]. In this respect, Business Process Management (BPM) is an established contemporary concept of process innovation that builds on Business Process Reengineering, a more radical approach, and Total Quality Management, a more incremental approach to process innovation. BPM integrates the two perspectives into an approach to process innovation that makes use of both radical and incremental efforts. While BPMdriven process innovation has been heavily researched in the context of eGovernment, the current literature has yet failed to understand the role of collaboration and networks in process innovation [16-18].

In this paper, we contribute to the study of collaboration and process innovation in the public sector by (1) developing and applying a governance theory framework for differentiating and comparing distinct types of collaboration. (2) We investigate empirically, whether organizations that are more mature in their process innovation initiatives feature different collaboration schemata. We thus provide an overview of future challenges for public sector process innovation with regard to involving process stakeholders. (3) We study a range of contextual factors and their effect on collaborative process innovation. These factors include financial stress, organizational size, and the level of internal process management knowledge.

The remainder of the paper is structured as follows. Firstly, we build a theoretical foundation for studying collaborative process innovation, by utilizing governance theory and drawing on the BPM literature. We then set out our hypotheses and research design, a quantitative study of 357 local governments in Germany. The presentation of results is followed by a discussion of the implications for both theory and practice. The final part of the paper is concerned with limitations and potentially fruitful avenues for future research.

\section{Theoretical Background}

\subsection{Business Process Management}

BPM is a key concept for both E-Government research and practice. It is an approach for analyzing and improving business processes, integrating both incremental and revolutionary predecessors as Business Process Reengineering or Total Quality Management. Thus, BPM is not only about a one-off reorganization of both organization and IT, but more a permanent activity of monitoring business processes and comparing their achieved results with the desired ones. Public sector organizations employ BPM in order to streamline business processes. This is often closely connected to the introduction of new information and communication technology and, hence, has become a key concept in E-Government research [9-14]. 
Successful BPM requires specific assets and capabilities which are costly to obtain. Contemporary research on business process change emphasizes that expertise, skills, and capabilities, as well as information systems and other assets are needed if success is to be achieved [19]. Capabilities include, for example, business process modeling or process analysis. Organizations that wish to build up such capabilities have to train their employees or hire experts in these areas. Assets include BPM suites or workflow management systems. In this respect, organizations have to purchase solutions. Hence, the capabilities and assets needed for successful BPM are associated with considerable costs.

In modern public and private sector organizations, BPM capabilities are obtained with the support of a plethora of actors. Stakeholders from both inside and outside the organizational boundaries are involved in BPM projects [18]. Moreover, organizations that become more mature in BPM are said to collaborate with more actors [20].

\subsection{Governance Theory}

Governance Theory differentiates between three forms of governance, hierarchy, network (or cooperation), and market [21]. The characteristics of each, especially with regards to BPM, are described below.

Hierarchy. A classical Weberian bureaucracy operates according to the governance form hierarchy, with the primary means of communication being routines. The actors involved are bound through employer/employee relationships. These relationships create a quite stable and reliable work environment, affecting both commitment among partners and handling of conflict. However, this governance form has one major downside. Due to contractual constraints, the flexibility of the organization is rather limited. A hierarchical organization is restricted in its choice of partners, at least for short-term decisions. It takes time to set up or terminate commitments such as labor contracts. A BPM-related example corresponding to this form of organization is a firm that deploys its own employees for a BPM-related task.

Network. The network form, as identified by Powell, is claimed to be based on complementary strengths and common interests among independent partners. Probably, the most important characteristics of a network are the relationships between its members, which constitute both the primary means of communications and the mechanism for solving conflict. According to Powell, the latter is due to member concerns about their own intra-network reputation. Organizations working against the network, such as through betrayal, will probably simply be expelled from the network, as the other members share a common interest. This is also a good example of network flexibility. In general, all network actors have to agree on new partners. However, changes in the network occur more frequently than in hierarchical settings. In a BPM context, organizations could improve inter-organizational operational processes along their supply chain.

Market. Economic actions relying on market mechanisms are regulated mainly by prices. Additionally, contracts and property-rights regulations provide guidance. As long as the market structure does not suffer from monopolies or lock-ins, this form provides the greatest flexibility, since the company is not bound to its partners, as it would be in hierarchical or network forms. This means, on the other hand, that partners are not necessarily interested in the fate of the company, such that Powell attests 
"low commitment" [21] among the partners. Even worse, the general atmosphere might be dominated by suspicion and control, with conflicts usually being resolved in court. Teece et al. also emphasize the risk of poor asset protection resulting from purely market-based arrangements [22]. In the sense of the present work, obtaining a BPM capability in the market can, for example, mean hiring external consultants who help the organization carry out complex BPM projects.

According to theory, the organization's choice between these three forms - the 'make-or-buy decision' [23] - depends on several aspects. Following Williamson's argumentation [24] and [25], Powell points out that "transactions that involve uncertainty about their outcome, that recur frequently and require substantial 'transaction-specific investments' - of money, time or energy that cannot be easily transferred - are more likely to take place within hierarchically organized firms" [21]. However, "exchanges that are straightforward, non-repetitive and require no transaction-specific investments will take place across a market interface" [21]. Furthermore, he comes to the conclusion that transactions performed within a hierarchy tend to be less efficient than market transactions, but market transactions tend to cause greater costs [21]. Thorelli adds the network-paradigm to the Williamson argument and explains its benefits. He claims that power, influence, and trust are cornerstones of the network paradigm [26]. Therefore, the downside of this concept is that managing and maintaining a network requires significant effort by all parties involved [26]. However the "effectiveness, efficiencies or risk-reduction gained in [network arrangements] is felt to exceed transaction costs of myriad spot transactions or the major resource commitments, difficulties of performance evaluation, etc. typically associated with all-out internalization" [26]. Error! Reference source not found. gives an overview of the major characteristics of the three forms of governance (see [21]).

Table 1. Stylized Comparison of Forms of Governance

\begin{tabular}{llll}
\hline Key Feature & Market & Network & Hierarchy \\
\hline Normative Basis & $\begin{array}{l}\text { Contract - Property } \\
\text { Rights }\end{array}$ & $\begin{array}{l}\text { Complementary } \\
\text { Strengths }\end{array}$ & $\begin{array}{l}\text { Employment } \\
\text { Relationship }\end{array}$ \\
$\begin{array}{l}\text { Means of } \\
\text { Communication }\end{array}$ & Prices & Relational & Routines \\
Degree of Flexibility & High & Medium & Low \\
Tone or Climate & $\begin{array}{l}\text { Precision and/or } \\
\text { Suspicion }\end{array}$ & $\begin{array}{l}\text { Open-ended, } \\
\text { 'mutual benefits' }\end{array}$ & $\begin{array}{l}\text { Formal, } \\
\text { bureaucratic }\end{array}$ \\
Extor Choices & Independent & Interdependent & Dependent \\
\hline
\end{tabular}

\section{Hypotheses}

In practice, all governance forms are observable with regard to public sector BPM. Organizations can rely on their own staff to implement process-related reforms (hierarchy). They can cooperate with other partners as local government associations or customers (in terms of citizens and local companies), or "buy" BPM capabilities in a 
market, e. g. from software or consulting companies. However, up to now, the choice of governance form (or governance mix) appears somewhat arbitrary. In this paper, we analyze the influence of several variables on the BPM governance form and formulate different hypothesis based on related theory (see Figure 1 for an overview of the hypotheses).

Firstly, BPM maturity refers to how mature an organization is with regards to BPM capabilities. It is regarded as exerting a considerable impact on the choice of collaboration. The BPM Maturity Model of Rosemann et al. [20] argues that maturing organizations include more and more actors from their respective hierarchy. Moreover, highly mature organizations are expected to manage processes collaboratively. Fisher coined the term "intelligent operating network" with respect to such situations [16]. Accordingly:

H1: The more mature an organization with regard to BPM capabilities, the more likely it is source its BPM capabilities using hierarchical, network, or market settings.

Secondly, one could assume that a relationship between the number of employees in an administration influences the choice of governance form. Here, we argue that larger organizations have more potential to fulfill BPM-related tasks using hierarchical sourcing.

H2: The more employees a municipal administration has, the more likely is it to source its BPM capabilities using hierarchical governance.

Thirdly, process improvement projects entail costs. This is especially true when the necessary resources are acquired through market relationships. Hence, organizations

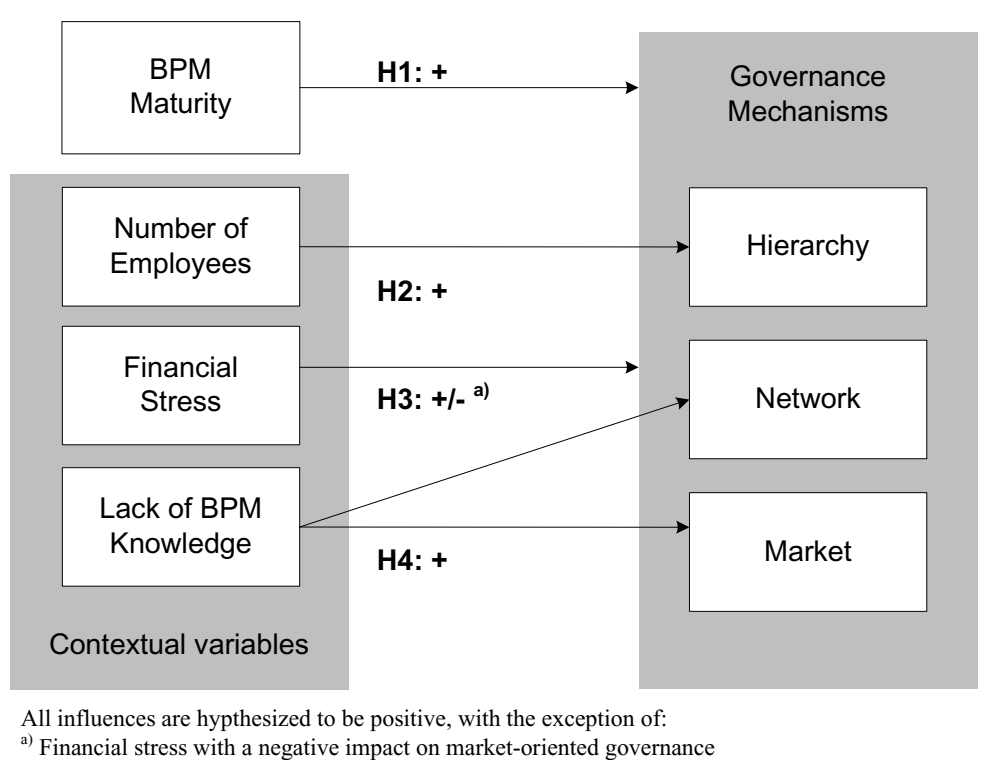

Fig. 1. Hypotheses 
that perceive their financial situation as critical are more likely to rely on internal or network resources and less likely to source from the market.

H3: The higher the level of perceived financial stress, the more likely the organization is to source its BPM capabilities using hierarchical or network settings and the less likely the use of market governance.

Fourthly, BPM projects require substantial knowledge. This knowledge may be related to tools, modeling techniques, project management skills, etc. Hence, one could argue that organizations that do not internalize this knowledge have to rely on external partners. In this context, we hypothesize that organizations with greater knowledge scarcity tend to rely on BPM resources sourced via cooperation or the market.

H4: The greater the amount of BPM knowledge scarcity in a municipal administration, the more likely it is to source its BPM capabilities using network or market governance.

\section{Research Methodology}

Data Collection. We collected the data for this study in 2008 using an online questionnaire. We invited 8,000 government officials, each responsible for BPM in a single local administration to participate. Hence, we contacted around two thirds of all $\sim 12,250$ local governments in Germany. We hoped to collect a homogeneous sample of all organizations in the public sector (at a local level), which should ensure a certain robustness of the data. With 357 completed questionnaires, we achieved a response rate of roughly $4.5 \%$. These organizations are distributed over all German large-area federal states (plus Berlin). We did not detect any participation bias.

Questionnaire. The questionnaire for the study was constructed with regard to both our presented hypotheses and the existing theory. However, for this specific study, only a part of all questions asked are relevant. Other questions focus, for example, on efforts to establish BI-solutions in public administrations. With regard to BPM Maturity, we relied on six common dimensions of BPM [19]. For the dependent variables, we asked for the perceived importance of relevant actors in both BPM agenda-setting and implementation [18] and [27]. Importance is, amongst others, such as frequency or strength, a criterion that is widely applied to measure links in social networks [28]. The constructs and the respective questions can be requested from the authors.

Data Analysis. After the data collection (online questionnaire), we employed SPSS 17.0.0 to analyze the structured data. In order to further understand the relationships between the constructs, we employed the partial least squares (PLS) path modeling algorithm [29-31]. We used the centroid weighting scheme, because it does not overestimate effects, as is the case with the factor weighting scheme [32]. The software package was SmartPLS [33]. The constructs were modeled using reflective indicators (a detailed discussion on formative versus reflective indicators can be found in Diamantopoulos [34]). Missing values were treated using the mean replacement algorithm [35]. This data analysis procedure enabled an evaluation of the above hypotheses. 


\section{Results}

We present our study results in a three-stepped approach. Firstly, we show the validity of our constructs (outer model) in terms of internal consistency and inter- vs. intraconstruct correlations. Secondly, we present the paths and their corresponding coefficients (outer model). Finally, although not a major focus of this study, we analyze the model with regard to the coefficient of determination.

Outer Model. The results derived using the above mentioned methodology are listed in Table 2. The internal consistency reliability (ICR) of all latent variables was measured with Cronbach's Alpha. In general, an ICR above .9 is considered as excellent, one between .7 and .9 as high, one between .5 and .7 as moderately high, and all others as low [36]. All reliabilities in our study are in the high or excellent range (note that BPM PreKnow and Number of employees were measured using single items) (Table 2).

Table 2. Measurement Model Estimation

\begin{tabular}{|l|r|r|r|r|r|r|r|r|r|r|}
\hline & ICR & Mean & S-Dev & 1 & 2 & 3 & 4 & 5 & 6 & 7 \\
\hline 1 Hierarchy & .86 & 4.33 & .59 & .77 & & & & & & \\
\hline 2 Network & .93 & 2.24 & .72 & .19 & .69 & & & & & \\
\hline 3 Market & .84 & 2.83 & .93 & .14 & .51 & .82 & & & & \\
\hline 4 BPM Maturity & .86 & 3.03 & .71 & .31 & .28 & .09 & .76 & & & \\
\hline 5 Number of Employees & 1.00 & 374 & 1257 & -.02 & -.06 & .05 & -.02 & 1.00 & & \\
\hline 6 Financial Stress & .91 & 3.21 & .95 & .09 & .20 & .09 & -.03 & .06 & .89 & \\
\hline 7 BPM Knowledge Lack & 1.00 & 1.89 & .80 & -.04 & .00 & .17 & -.31 & -.04 & .01 & 1.00 \\
\hline
\end{tabular}

a) ICR: Internal consistency reliability (Cronbach's Alpha)

b) Diagonal elements are the square root of the shared variance between the constructs and their measures

c) Off-diagonal elements are correlations between constructs

Moreover, correlations between the constructs were lower than the square roots of the shared variance between the constructs and their measures in every case. According to Fornell and Larker [37], this indicates convergent and discriminant validity. We employed a bootstrapping method (500 iterations) using randomly selected subsamples to test the significance of our PLS model. Analyzing the item loadings, we observed that our latent variables are indeed measured by the corresponding items (Table 3).

Inner Model. In our proposed model, not all paths are proven to be significant using the bootstrapping method (Table 4). We observe high positive influences of Lack of BPM Knowledge on Market, of Perceived Financial Limits on Network, and of BPM maturity on all three governance types. These 5 paths are also shown to be significant. All other hypotheses were falsified by our analysis. 
Table 3. Item Loadings

\begin{tabular}{|c|c|c|}
\hline $\mathbf{L V}$ & Item & Loading \\
\hline \multirow{6}{*}{ 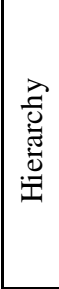 } & AS_MAY & $.7357 * * *$ \\
\hline & AS_DH & $.8550 * * *$ \\
\hline & AS_EMP & $.7543 * * *$ \\
\hline & I_MAY & $.6982 * * *$ \\
\hline & I_DH & $.8673 * * *$ \\
\hline & I_EMP & $.7057 * * *$ \\
\hline \multirow{4}{*}{ 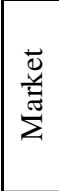 } & AS_CONS & $.7939 * * *$ \\
\hline & AS_SOFT & $.8585^{* * *}$ \\
\hline & I_CONS & $.7906 * * *$ \\
\hline & I_SOFT & .8539 *** \\
\hline \multirow{6}{*}{ 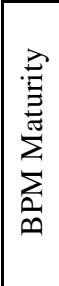 } & MAT1_SA & $.7295 * * *$ \\
\hline & MAT2_GOV & $.7498 * * *$ \\
\hline & MAT3_MET & $.6626^{* * *}$ \\
\hline & MAT4_IT & $.7736 * * *$ \\
\hline & MAT5_PEO & $.8532 * * *$ \\
\hline & MAT6_CUL & $.7890 * * *$ \\
\hline \multirow{4}{*}{ 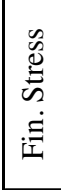 } & PFL1 & $.9228 * * *$ \\
\hline & PFL2 & $.9037^{* * *}$ \\
\hline & PFL3 & $.9335 * * *$ \\
\hline & PFL4 & $.7729 * * *$ \\
\hline
\end{tabular}

\begin{tabular}{|c|c|c|}
\hline $\mathbf{L V}$ & Item & Loading \\
\hline \multirow{16}{*}{ 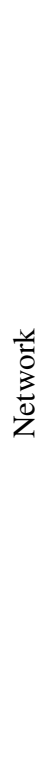 } & AS_CM & $.6302 * * *$ \\
\hline & AS_PP & $.7184 * * *$ \\
\hline & AS_1TO & $.7021 * * *$ \\
\hline & AS_2TO & $.7459 * * *$ \\
\hline & AS_CIT & $.6585 * * *$ \\
\hline & AS_COM & $.6591 * * *$ \\
\hline & AS_LGA & $.7108 * * *$ \\
\hline & AS_OLG & $.5685 * * *$ \\
\hline & I_CM & $.6402 * * *$ \\
\hline & I_PP & $.7058 * * *$ \\
\hline & I_1TO & $.7019 * * *$ \\
\hline & I_2TO & $.7518 * * *$ \\
\hline & I_CIT & $.7232 * * *$ \\
\hline & I_COM & $.7278 * * *$ \\
\hline & I_LGA & $.7414 * * *$ \\
\hline & I_OLG & $.5899 * * *$ \\
\hline
\end{tabular}

"Lack of BPM Knowledge" and
"Number of Employees" were
measured using single items.

Table 4. Path Coefficients

\begin{tabular}{|l|l|l|l|}
\hline & Hierarchy & Network & Market \\
\hline $\mathrm{R}^{2}$ & .1052 & .1306 & .0632 \\
\hline BPM Maturity & $.3107 * * *$ & $.3078^{* * *}$ & $.1613^{* *}$ \\
\hline Number of Employees & -.0202 & -.0633 & .0556 \\
\hline Financial Stress & .0992 & $.2098^{* * *}$ & .0902 \\
\hline Lack of BPM Knowledge & n.a. & .0902 & $.2205 * * *$ \\
\hline
\end{tabular}

Coefficient of Determination. The coefficient of determination $\left(\mathrm{R}^{2}\right)$ is defined as the proportion of variance in the data explained by the statistical model (and not by random error terms or constructs not included). In our analysis, we did not focus on the coefficient of determination, but on the influence of BPM PreKnowledge, Perceived Financial Limits, Number of employees, and BPM maturity on the choice of BPM governance. Hence, the $\mathrm{R}^{2}$ of our model is comparably slow. However, we can explain about 6.5 to $13 \%$ of the variance in the dependent variables (Table 4). 


\section{Discussion}

Our study suggests that several factors influence the choice of governance mechanism for public sector BPM. Relating to our research question, we observe a high influence of BPM maturity as well as of other contextual variables (Fig. 2).

Firstly, organizations that are more mature are more likely to collaborate with any BPM actors. In this respect, the influence of BPM maturity on all market, network, and hierarchy is positive. Hence, our first hypothesis is confirmed.

Secondly, we assumed that a larger number of employees in local administration would lead to a greater reliance on BPM capabilities sourced through hierarchical governance settings. However, our study seems to falsify the related hypothesis $\mathrm{H} 2$ : The choice of governance mechanism is not related to the size of the organization.

Our third hypothesis was that a higher level of financial stress would lead to greater collaboration in hierarchical and network settings and a lower reliance on market actors. However, our study reveals a different picture. Financial stress is unrelated to hierarchy and market settings. Apparently, the inclusion of such actors is not dependent on the financial situation of the respective organization. Yet, according to our study, a greater financial stress leads to greater collaboration with network actors. In this respect, we assume that organizations in similar settings (e. g. neighboring cities) collaborate both with each other and with other actors, e. g. government associations or citizens and local companies, once they face financial stress.

Fourthly, as hypothesized, a lack of BPM knowledge in municipal administration leads to a higher level of collaboration with market actors. However, the other part of H4 is falsified: BPM knowledge is not related to sourcing BPM capabilities in network governance.

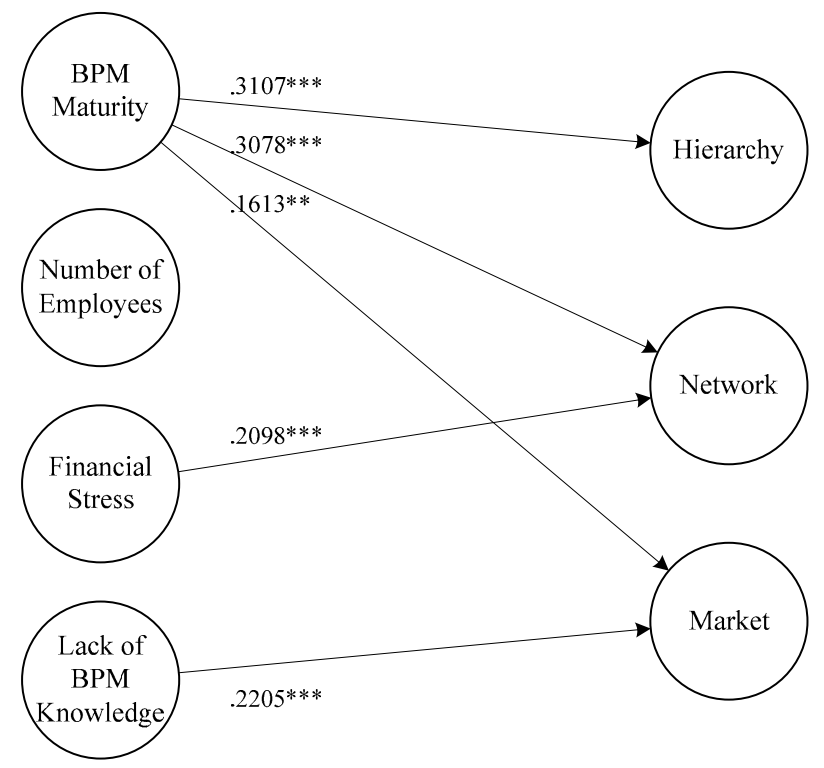

Fig. 2. Significant influences 
The contemporary development of BPM capabilities in local administrations is a major influence on the collaboration type in terms of the choice of governance mechanisms. The more mature organizations become in their BPM capabilities, the more they are to collaborate with all actors, independent of market, network, or hierarchy sourcing. However, this is not the only influence. Contextual factors are important for the choice of governance form, too.

This study contributes the influence of BPM development on collaboration and governance mechanisms to theory on BPM capability development or BPM maturity. The continuous development of BPM capabilities in public sector organizations leads inevitably to a higher importance of all market, network, and hierarchy actors. Organizations that improve their capabilities to change and improve business processes will collaborate more intensively. However, contextual factors such as a lack of BPM knowledge or financial stress are also important. Firstly, local government organizations facing financial stress collaborate with such network actors as other local governments, local government associations, or customers in the form of local companies and citizens. Secondly, local governments that lack BPM-related knowledge are forced to obtain it through market mechanisms, i.e. buy the necessary knowledge from consulting companies.

Moreover, this study extends governance theory to the fields of BPM and public management. Firstly, it is important to note that successful BPM can be achieved with the aid of multiple actors using different governance mechanisms. However, the more mature organizations become in BPM, the more they collaborate. Secondly, future governance theory studies should include such contextual factors as financial stress or lacks of knowledge in order to investigate the choice of governance mechanisms.

For both practitioners and scholars, it is important to note that the role of process managers changes over time. In immature organizations, process managers can be described as "arm-chair-like lone cowboys". However, once organizations start to mature, the role changes to that of an "orchestrator of different actors." Process managers in future public organizations (assuming a positive development of capabilities), must be able to collaborate with actors from different governance mechanisms. Hence, their skill set will also have to change.

Furthermore, given that organizations facing financial stress evidently collaborate closely with network actors and typical local administrations face financial stress, information technology supporting this collaboration needs to be designed. Both theory and practice have to come up with solutions for methods and tools to support network collaboration. In this context, design science approaches appear to be fruitful.

The study suggests that local administrations as clients of consultancy companies (market governance) have to become more professional (client professionalization) and incorporate the knowledge generated in consulting projects more effectively. So far a lack of BPM knowledge leads to greater collaboration with market actors. However, this collaboration induces costs that can be avoided with the aid of an active knowledge transfer from consultancies to local governments. In this respect, the results of BPM consulting projects need to become more sustainable. However, not only consultancies are to blame for the prevailing lack of sustainability, but also local governments as clients. Government professionals are advised to improve their knowledge management in order to get the best out of consulting projects. Researchers can support this process with both the design of appropriate tools and an analysis of current shortcomings. 
Our study is subject to limitations. Firstly, we only analyzed one country. While we believe that the results are fairly typical for Western countries, they may be different for other cultural settings (in particular Asia or Africa). Secondly, our study yields low coefficients of determination. Hence, other contextual factors not covered by our study could influence the choice of governance mechanism. Thirdly, the concept of BPM maturity is questioned in contemporary research. Other forms of describing the capability development could be valuable, too [38]. Fourthly, one could question whether public sector organizations understand the concept of BPM in the same way as scholarship. As we introduced the concept shortly in the questionnaire hope to overcome this limitation. However, slight misunderstandings are still possible.

Acknowledgement. This paper was written in the context of the research project KollaPro (promotional reference 01FL10004) funded by the German Federal Ministry of Education and Research. We would like to thank the reviewers and chairs for their guidance and helpful remarks as well as our student assistants for their support in the data collection process.

\section{References}

1. Pollitt, C., Bouckaert, G.: Public management reform: a comparative analysis, 2nd edn. Oxford University Press, Oxford (2004)

2. Lenk, K.: Der Staat am Draht. Electronic Government und die Zukunft der öffentlichen Verwaltung - eine Einführung. Berlin (2004a)

3. Reichard, C.: Local public management reforms in Germany. Public Administration 81(2), 345-363 (2003)

4. von Hippel, E.: Innovation by User Communities: Learning From Open-Source Software. MIT Sloan Management Review 42(4), 82-86 (2001)

5. Chesbrough, H.W.: Open Innovation: The New Imperative for Creating and Profiting from Technology. Harvard Business School Press, Boston (2003)

6. Gil-Garcia, R., Chengalur-Smith, I.S., Duchessi, P.: Collaborative E-Government: Impediments and Benefits of Information-Sharing Projects in the Public Sector. European Journal of Information Systems 16(2), 121-133 (2007)

7. Sorrentino, M., Ferro, E.: Does the Answer to eGovernment Lie in Intermunicipal Collaboration? An Exploratory Italian Case Study. In: Wimmer, M.A., Scholl, H.J., Ferro, E. (eds.) EGOV 2008. LNCS, vol. 5184, pp. 1-12. Springer, Heidelberg (2008)

8. Becker, J., Niehaves, B., Ortbach, K.: Does the Answer Lie in Collaboration? - A Case Study on E-Government and Societal Aging. In: Proceedings of the 17th European Conference on Information Systems (ECIS), Verona, Italy (2009)

9. Traunmüller, R., Wimmer, M.: Directions in E-Government: Processes, Portals, Knowledge. In: Proceedings of the International Workshop On the Way to Electronic Government in Conjunction with DEXA, Munich, Germany, September 3- 7, pp. 313-317. IEEE Computer Society Press, Los Alamitos (2001)

10. Kubicek, H., Millard, J., Westholm, H.: Methodology for Analysing the Relationship between the Reorganisation of the Back Office and Better Electronic Public Services. In: Traunmüller, R. (ed.) EGOV 2003. LNCS, vol. 2739, pp. 199-206. Springer, Heidelberg (2003) 
11. Palkovits, S., Wimmer, M.: Processes in e-Government - A Holistic Framework for Modelling Electronic Public Services. In: Proceedings of the 2nd International Conference on EGovernment, Prague, Czech Republic, pp. 213-219 (2003)

12. Scholl, H.J.: The dimensions of business process change in electronic government. In: Huang, W., Siau, K., Wei, K. (eds.) Electronic government strategies and implementation, pp. 44-67. Idea Group Pub., Hershey (2004)

13. Scholl, H.J(J.), Fidel, R., Liua, S(M.), Paulsmeyer, M., Unsworth, K.: E-Government Field Force Automation: Promises, Challenges, and Stakeholders. In: Wimmer, M.A., Scholl, J., Grönlund, Å. (eds.) EGOV. LNCS, vol. 4656, pp. 127-142. Springer, Heidelberg (2007)

14. Niehaves, B., Malsch, R.: Democratizing Process Innovation? On Citizen Involvement in Public Sector BPM. In: Wimmer, M.A., Scholl, H.J., Janssen, M., Traunmüller, R. (eds.) EGOV 2009. LNCS, vol. 5693, pp. 245-256. Springer, Heidelberg (2009)

15. Weber, I., Sure, Y.: Towards an Implementation of the EU Services Directive with Semantic Web Services. In: 12th International Conference on Business Information Systems, Poznan, Poland, pp. 217-227 (2009)

16. Fisher, D.M.: The Business Process Maturity Model. A Practical Approach for Identifying Opportunities for Optimization. BPTrends 9(4) (2004)

17. Rosemann, M., de Bruin, T.: Towards a Business Process Management Maturity Model. In: Bartmann, D., Rajola, F., Kallinikos, J., Avison, D., Winter, R., Ein-Dor, P., Becker, J., Bodendorf, F., Weinhardt, C. (eds.) Proceedings of the 13th European Conference on Information Systems (ECIS), Regensburg, pp. 521-532 (2005b)

18. Niehaves, B., Plattfaut, R.: Collaborative Business Process Management: Status Quo and Quo Vadis. Business Process Management Journal 17(3), 384-402 (2011)

19. Rosemann, M., vom Brocke, J.: Handbook on Business Process Management. Springer, Heidelberg (2010)

20. Rosemann, M., de Bruin, T., Power, B.: A model to measure business process management maturity and improve performance. In: Jeston, J., Nelis, J. (eds.) Business Process Management, pp. 299-315. Butterworth Heinemann, Burlington (2006)

21. Powell, S.W.: Neither market nor hierarchy: Network forms of organization. Research In Organizational Behavior 12(1), 295-336 (1990)

22. Teece, D.J., Pisano, G., Shuen, A.: Dynamic Capabilities and Strategic Management. Strategic Management Journal 18(7), 509-533 (1997)

23. Walker, G., Weber, D.: A Transaction Cost Approach to Make-or-Buy Decisions. Administrative Science Quarterly 29(3), 373-391 (1984)

24. Williamson, O.E.: Markets and Hierarchies: Analysis and Antitrust Implications. Free Press, New York (1975)

25. Williamson, O.E.: The Institutions of Governance. The American Economic Review 88(2), 75-79 (1998)

26. Thorelli, H.B.: Networks: Between markets and hierarchies. Strategic Management Journal 7(1), 37-51 (1986)

27. Becker, J., Niehaves, B., Plattfaut, R.: Stakeholder Involvement in Business Process Management Agenda-Setting and Implementation. In: Proceedings of the 16th Americas Conference on Information Systems (AMCIS), Lima, Peru (2010)

28. Rosen, D., Barnett, G.A., Kim, J.H.: Social networks and online environments: when science and practice co-evolve. Social Network Analysis and Mining 1(1), 27-42 (2010)

29. Chin, W.W., Dibbern, J.: Permutation Based Procedure for Multi-Group PLS Analysis: Results of Tests of Differences on Simulated Data and a Cross of Information System Services between Germany and the USA. In: Handbook of Partial Least Squares: Concepts, Methods and Applications in Marketing and Related Fields. Springer, Heidelberg (2009) 
30. Marcoulides, G.A., Chin, W.W., Saunders, C.: A Critical Look at Partial Least Squares Modeling. MIS Quarterly 33(1), 171-175 (2009)

31. Henseler, J., Fassott, G.: Testing Moderating Effects in PLS Path Models: An Illustration of Available Procedures. In: Handbook of Partial Least Squares: Concepts, Methods and Applications in Marketing and Related Field. Springer, Heidelberg (2009)

32. Wilson, B., Henseler, J.: Modeling Reflective Higher-Order Constructs using Three Approaches with PLS Path Modeling: A Monte Carlo Comparison. In: Thyne, M., Deans, K.R., Gnoth, J. (eds.) Australian and New Zealand Marketing Academy Conference, pp. 791-800. University of Otago, New Zealand (2007)

33. Ringle, C.M., Wende, S., Will, S.: SmartPLS 2.0 (M3) Beta. Hamburg (2005), http: / / www. smartpls.de

34. Diamantopoulos, A., Siguaw, J.A.A.: Formative versus Reflective Indicators in Organizational Measure Development: A Comparison and Empirical Illustration. British Journal of Management 17(4), 263-282 (2006)

35. Afifi, A.A., Elashoff, R.M.: Observations in Multivariate Statistics: I. Review of the Literature. Journal of the American Statistical Association 61(315), 595-604 (1966)

36. Hinton, P.R., Brownlow, C., McMurvay, I., Cozens, B.: SPSS explained. Routledge Inc., East Sussex (2004)

37. Fornell, C., Larker, D.F.: Evaluating Structural Equation Models with Unobservable Variables and Measurement Error: Algebra and Statistics. Journal of Marketing Research 18(3), 382-388 (1981)

38. Plattfaut, R., Niehaves, B., Pöppelbuß, J., Becker, J.: Development of BPM Capabilities - Is Maturity the Right Path? In: Proceedings of the 19th European Conference on Information Systems (ECIS), Helsinki, Finland (2011) 